\title{
The unusual long track and rapid intensification of very severe cyclone Ockhi
}

\author{
Vineet Kumar Singh ${ }^{1,2, *}$, M. K. Roxy ${ }^{1}$ and Medha Deshpande ${ }^{1}$ \\ ${ }^{1}$ Indian Institute of Tropical Meteorology, Ministry of Earth Sciences, Pune 411008 , India \\ ${ }^{2}$ Department of Atmospheric and Space Sciences, Savitribai Phule Pune University, Pune 411007 , India
}

Cyclone Ockhi in November 2017, was the first very severe cyclone to form over the Lakshadweep Sea since 1925, resulting in a death toll of 844 in India and Sri Lanka. The distance travelled, duration and accumulated cyclone energy were significantly larger for cyclone Ockhi, in comparison with the climatological cyclone records. It intensified rapidly from a depression to a cyclone in a span of $9 \mathrm{~h}$ and further to a very severe cyclone in $24 \mathrm{~h}$. The present study shows that the Madden-Julian Oscillation and warm oceanic conditions provided favourable dynamic and thermodynamic conditions for the genesis of cyclone Ockhi. The favourable thermodynamic conditions due to warm sea-surface temperature over southeast Arabian Sea also helped in the intensification of the cyclone during its early and mature stages. Meanwhile, the unusual long track was steered by upper-level winds. The vital role of ocean temperature in the genesis and rapid intensification of the cyclone highlights the need for efficiently incorporating the coupled oceanatmospheric conditions in cyclone forecast models. The Arabian Sea needs to be closely monitored for future storms since climate projections indicate that the rapid warming in the basin will continue into the future.

Keywords: Madden-Julian Oscillation, ocean warming, rapid intensification, thermodynamics, very severe cyclone.

TROPICAL cyclones are among the most destructive natural disasters on earth. The north Indian Ocean, including the Arabian Sea and the Bay of Bengal, accounts for about $7 \%$ of the global tropical cyclones ${ }^{1}$. The cyclone frequency in this region varies between 1 and 3 in the pre-monsoon (March-May), and 2 and 5 in the postmonsoon (October-December) season ${ }^{2}$. The socio-economic impact of tropical cyclones over India is considerable due to the densely populated coastal districts of the country with a population of 170 million-projected to become threefold by 2060 (ref. 3). Cyclone Ockhi, which formed on 29 November 2017, caused a trail of destruction. While 365 fatalities were reported from India ${ }^{4}$, a total of 884 casualties were reported for India and

\footnotetext{
*For correspondence. (e-mail: vineetsingh.jrf@tropmet.res.in)
}

Sri Lanka ${ }^{5}$. About 13,000 ha of crops was affected by this cyclone and 7654 animals were reported dead in India ${ }^{6}$.

Cyclone Ockhi developed as a depression on 29 November 20170300 UTC in the Lakshadweep Sea (subsea of the Arabian Sea), south of Cape Comorin (Figure $1 a$ and $b$ ). It intensified from a depression into a cyclonic storm in a span of $9 \mathrm{~h}$. Based on the reference period (1990-2016), for post-monsoon (October-December) cyclones in the north Indian Ocean (including Arabian Sea and Bay of Bengal), it takes $24 \mathrm{~h}$ for a system to intensify from a depression to a cyclonic storm. Thus, cyclone Ockhi intensified from a depression to a cyclonic storm very quickly, compared to the climatological time taken for such intensification. Despite considerable improvements in the prediction of genesis, intensity and track of cyclones in the north Indian Ocean in the recent decade $^{7}$, most of the models failed to capture the genesis of cyclone Ockhi in advance and its rapid intensification in the initial stage (depression to a cyclonic storm in $9 \mathrm{~h}$ ). The model forecasts could capture this system only 1-2 days prior to its formation ${ }^{8}$. From 1 December 0000 UTC to 2 December 0000 UTC, it underwent rapid intensification again, gaining $30 \mathrm{kt}\left(15.4 \mathrm{~m} \mathrm{~s}^{-1}\right)$ in a span of $24 \mathrm{~h}$ (Figure $2 a$ ), and reaching a very severe cyclonic storm category with a wind speed of $80 \mathrm{kt}\left(41.2 \mathrm{~m} \mathrm{~s}^{-1}\right)$ over the southeast Arabian Sea. It attained a peak wind speed of $85 \mathrm{kt}\left(43.7 \mathrm{~m} \mathrm{~s}^{-1}\right)$ with a well-defined eye by 2 December 0600 UTC. It also became the first very severe cyclonic storm to form in the Lakshadweep Sea since 1925 (ref. 9). The models failed to capture this intensification in advance $^{8}$. From 4 December 1500 UTC, cyclone Ockhi started losing strength, and by 5 December 0300 UTC, it weakened to a cyclonic storm. Thereafter, it weakened rapidly to a depression by 5 December 1500 UTC, over the northeast Arabian Sea (Figure $1 b$ ). During its entire lifespan, cyclone Ockhi travelled a distance of $2538 \mathrm{~km}$ (ref. 8).

The lack of ability of the models to capture the genesis with high lead time and the underestimation of cyclone intensity show that in spite of the improvement in forecasting skills of models, there are still uncertainties in the cyclone forecasts using state-of-the-art models. These uncertainties could be due to the lack of model skill in representing ocean-atmospheric coupling and ocean subsurface conditions ${ }^{10}$. 

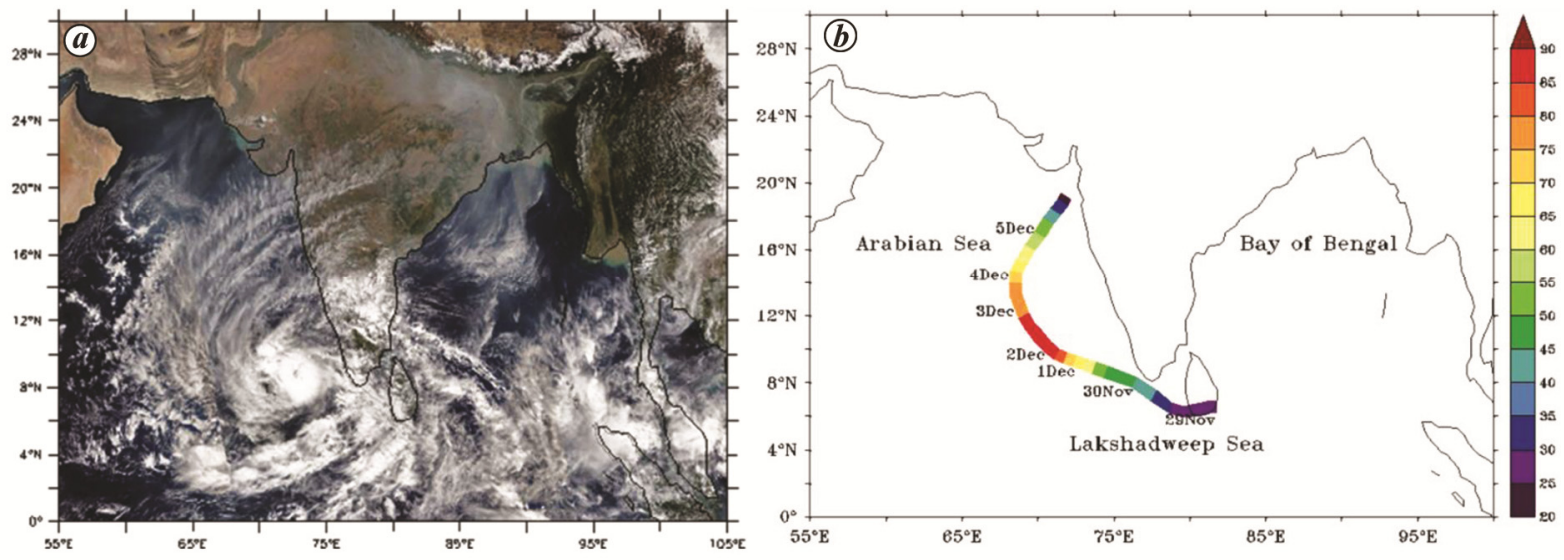

Figure 1. $\boldsymbol{a}$, Cyclone Ockhi as on 30 November 2017 (image credit: NASA/NOAA/NRL). $\boldsymbol{b}$, Track of cyclone Ockhi. Colour denotes wind speed $(\mathrm{kt})$ along the track.

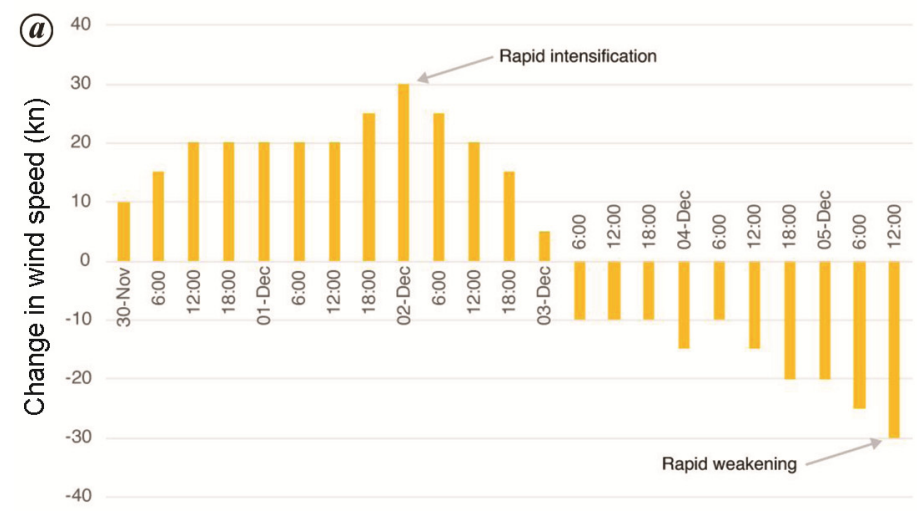

Date and time (UTC)

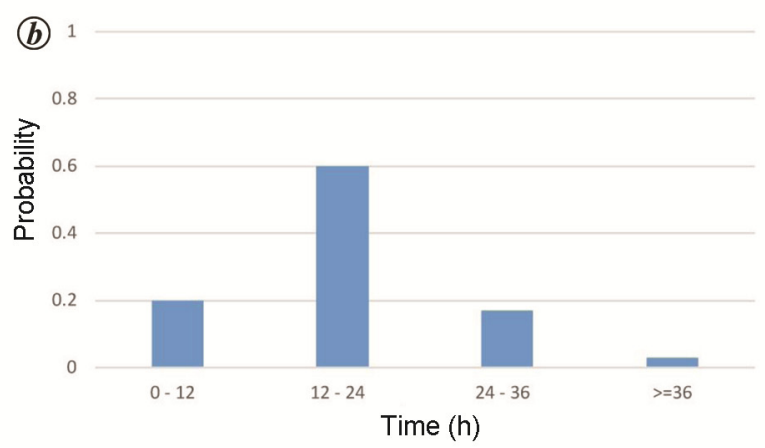

Figure 2. $\boldsymbol{a}$, Change in maximum surface wind (kt/day) during the period 30 November-5 December 2017. $\boldsymbol{b}$, Probability distribution of time taken (h) by a tropical disturbance to intensify from depression to cyclonic storm in the north Indian Ocean during the post-monsoon season for the period 1990-2016.

Therefore, the present study aims to understand the ocean-atmospheric factors responsible for the genesis, rapid intensification and long track of cyclone Ockhi. Earlier studies have shown that Madden-Julian Oscillation (MJO), which is an eastward-propagating band of enhanced convection in the tropical regions, plays a vital role in the genesis of cyclones in the north Indian Ocean by providing favourable background atmospheric conditions $^{11,12}$. Therefore, in this study we also explored the role of MJO in the genesis of cyclone Ockhi.

\section{Data and methodology}

In order to study the genesis, track and intensity of cyclone Ockhi, the cyclone track and wind speed data were obtained from India Meteorological Department (IMD) . $^{8}$ The classification of cyclones into different categories used in this study is based on IMD's Forecaster's Guide $^{13}$. The data on cyclones for the north Indian Ocean (Arabian Sea and Bay of Bengal) during the period 1990-
2016 for post-monsoon season (October-December) were obtained from the Regional Specialized Meteorological Centre (RSMC), New Delhi, as archived in the International Best Track Archive for Climate Stewardship (IBTrACS) v03r10 (ref. 14).

To study the ocean and atmospheric conditions associated with cyclogenesis and intensification, we obtained daily sea-surface temperature (SST) from the NOAA high-resolution SST dataset (https://www.esrl.noaa. $\mathrm{gov} / \mathrm{psd} /$ ) at a resolution of $0.25^{\circ} \times 0.25^{\circ}$ (ref. 15). Specific humidity (integrated over $850-500 \mathrm{hPa}$ ), convective available potential energy (CAPE), winds, air temperature and relative humidity data were obtained from the ERA-Interim reanalysis dataset at a resolution of $0.75^{\circ} \times 0.75^{\circ}$ (ref. 16). To denote the thermodynamic conditions, equivalent potential temperature $\left(\theta_{\mathrm{e}}\right)$ was calculated based on air temperature and specific humidity from the ERA-Interim reanalysis dataset. The equivalent potential temperature of an air parcel increases with increase in the water vapour content and temperature. The 
vertical profile of equivalent potential temperature in the atmosphere can be used as a tool to determine the stability of the lower atmospheric column ${ }^{17}$. An increase in equivalent potential temperature with height may lead to stable atmospheric conditions. On the other hand, a decrease in equivalent potential temperature with height may lead to unstable atmospheric conditions favourable for the formation of cyclones ${ }^{18}$. Therefore, we estimated the difference in equivalent potential temperature between 1000 and $700 \mathrm{hPa}$, to understand the role of thermodynamic conditions leading to instability of the lower atmospheric column and enhanced convective activity.

$$
\Delta \theta_{\mathrm{e}}=\theta_{\mathrm{e} 1000}-\theta_{\mathrm{e} 700} .
$$

In addition, we estimated the accumulated cyclone energy (ACE) of the cyclone Ockhi. ACE accounts for the combined strength and duration of tropical cyclones ${ }^{19,20}$. It is calculated by summing the squares of the six-hourly maximum sustained surface wind speed $(\mathrm{kt})$ during the duration when the system has a wind speed of $35 \mathrm{kt}\left(18 \mathrm{~m} \mathrm{~s}^{-1}\right)$ or higher. The number is divided by 10,000 for ease of interpretation (eq. (2)). ACE is estimated as follows

$$
\mathrm{ACE}=10^{-4} \sum v^{2}
$$

where $v$ is the maximum sustained wind speed $(\mathrm{kt}) \mathrm{ob}$ tained from $\mathrm{IMD}^{8}$.

The genesis potential parameter (GPP) was used to identify the signature of the cyclogenesis of cyclone Ockhi. GPP developed by Kotal et al. ${ }^{21}$, was used to identify the potential zone of cyclogenesis in the north Indian Ocean, based on two thermodynamic and two dynamic parameters. Relative vorticity is one of the important dynamic parameters utilized in estimating GPP since it is vital for cyclone formation, as high relative vorticity provides conducive conditions for enhanced convection ${ }^{18}$. Relative humidity is one of the thermodynamic variables taken into consideration for calculating GPP, since sufficient moistening of middle atmosphere is a necessary condition for genesis and intensification of cyclones ${ }^{18}$. Vertical wind shear of horizontal winds is one of the dynamic parameters included in the estimation of GPP, since low wind shear favours cyclone formation as it leads to reduction in the loss of moisture and latent heat energy through ventilation ${ }^{22}$. The temperature difference between the lower and middle atmosphere is the other thermodynamic parameter included in its calculation, as it provides atmospheric instability necessary for the development of a cyclone ${ }^{23}$. GPP is estimated based on all these atmospheric variables important for cyclone formation $^{21}$

$$
\begin{aligned}
\mathrm{GPP} & =\left(\xi_{850} \times M \times I\right) / S, \quad \text { if } \xi_{850}>0, M>0 \text { and } I>0, \\
& =0, \quad \text { if } \xi_{850} \leq 0, M \leq 0 \text { or } I \leq 0,
\end{aligned}
$$

where $\xi_{850}$ is the low-level relative vorticity at $850 \mathrm{hPa}$; $M$ the middle troposphere relative humidity defined by the formula $M=(\mathrm{RH}-40) / 30$, where $\mathrm{RH}$ is the average relative humidity between 700 and $500 \mathrm{hPa} ; I$ the middle troposphere instability which is the temperature difference $\left({ }^{\circ} \mathrm{C}\right.$ ) between 850 and $500 \mathrm{hPa}$ and $S$ is the vertical wind shear of horizontal winds between 200 and $850 \mathrm{hPa}$ $\left(\mathrm{m} \mathrm{s}^{-1}\right)$. This GPP index is based on atmospheric parameters and does not consider ocean parameters. Hence, in order to study the role of ocean conditions on cyclogenesis, a modified GPP was used, which incorporates both ocean and atmosphere parameters ${ }^{24}$.

$$
\text { Modified GPP }=(\text { GPP } \times \text { TCHP }) / 40,
$$

where TCHP is the tropical cyclone heat potential which is a measure of the ocean heat content from the surface to the $26^{\circ} \mathrm{C}$ isotherm depth ${ }^{25}$.

TCHP is computed as $^{25}$

$$
\mathrm{TCHP}=\rho C_{\mathrm{p}} \int_{0}^{D 26}(T-26) \mathrm{d} z
$$

where $\rho$ is the density of water above $26^{\circ} \mathrm{C}$ isotherm, $C_{\mathrm{p}}$ the specific heat of seawater at constant pressure, $T$ the average temperature of two consecutive layers with a depth increment of $\mathrm{d} z$ and $D 26$ is the depth of the $26^{\circ} \mathrm{C}$ isotherm (m). Daily subsurface temperature was obtained from the operational Mercator global ocean analysis and forecast system (http://marine.copernicus.eu) at $1 / 12^{\circ}$ horizontal resolution and 50 vertical levels with a higher vertical resolution near the surface. TCHP was computed at every grid point from seven days prior till the genesis of the cyclone.

Outgoing longwave radiation (OLR) was obtained from the NCEP-NCAR reanalysis dataset ${ }^{26}$. Vertical wind shear of horizontal winds was computed based on 200 and $850 \mathrm{hPa}$ winds. Daily anomalies of all parameters were obtained by removing the daily means based on the reference period from 1979 to 2017. Since the focus of the study is on the genesis, intensification and track of the cyclone, analysis of the role of various thermodynamic and ocean parameters in the genesis and intensification of cyclone Ockhi was carried out from seven days before cyclogenesis of the cyclone till its dissipation. However, the figures are displayed only for the days when the observed anomalies were significant (three days before the cyclogenesis).

The real-time multivariate MJO (RMM) index which is used to study MJO strength and its phases are obtained from the Australian Bureau of Meteorology (http://www. bom.gov.au/climate/mjo/). Its different phases denote the region in which the $\mathrm{MJO}$-associated convection is active. Space-time filtered OLR anomalies were utilized, based on the methodology adapted from Wheeler and Hendon ${ }^{27}$. 


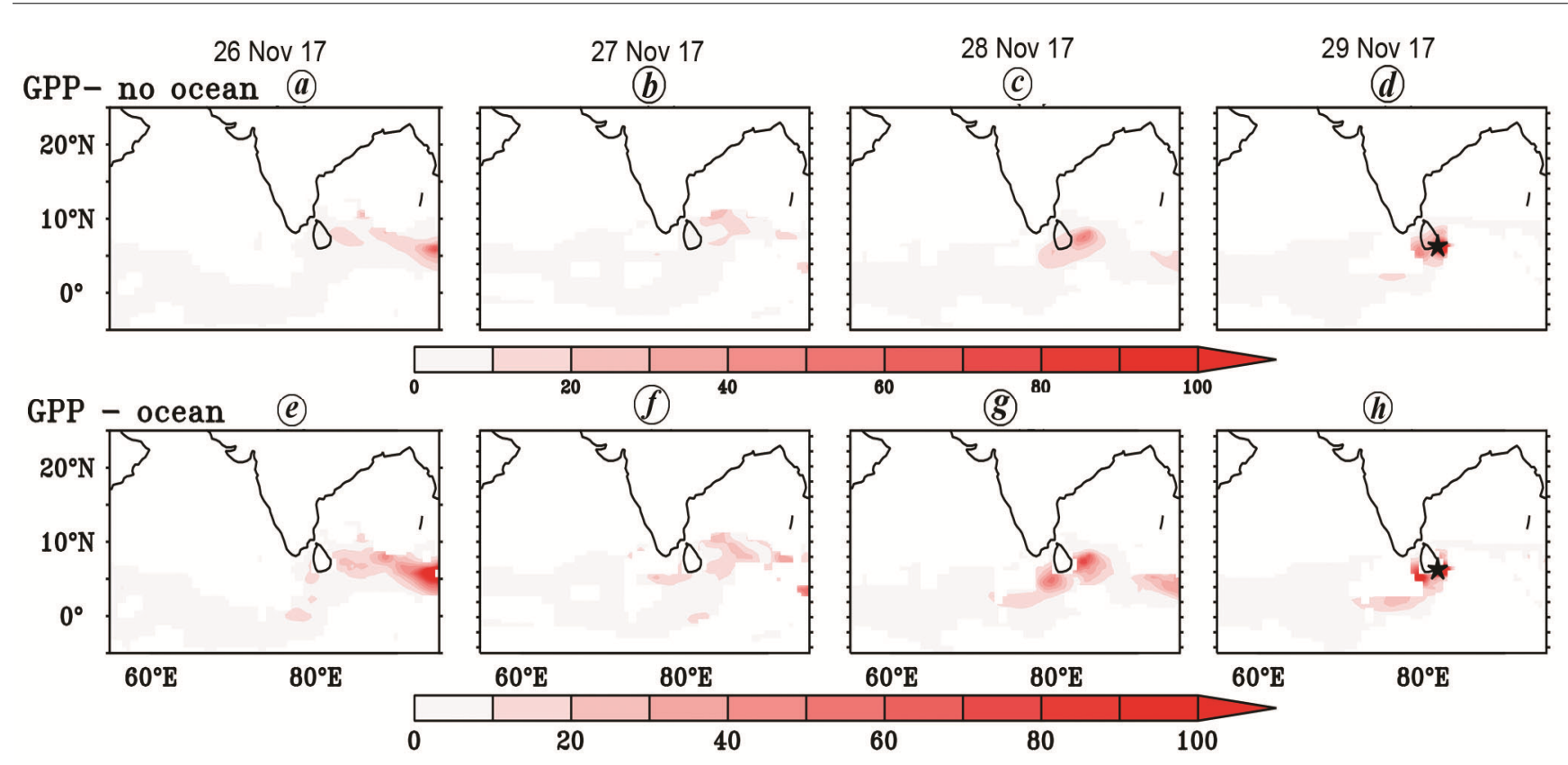

Figure 3. Genesis potential parameter (shaded) without $(\boldsymbol{a}-\boldsymbol{d})$ and with $(\boldsymbol{e}-\boldsymbol{h})$ ocean parameters from 26 to 29 November 2017 . Black star denotes the genesis of cyclone Ockhi.

\section{Results and discussion}

\section{Genesis of cyclone Ockhi and role of Madden-Julian Oscillation}

In order to compare the role of the ocean and atmospheric conditions on the genesis of cyclone Ockhi, we estimated GPP based on atmosphere-only parameters and a modified-GPP which incorporates ocean conditions. The atmosphere-only GPP (eq. (3)) was in the range 10-20 over the southwest Bay of Bengal and Cape Comorin area in the Arabian Sea on 26 and 27 November. A threshold of GPP $\geq 30$ has been used by IMD to identify the potential zone for cyclogenesis ${ }^{28}$. On 28 November 2017, one day prior to cyclone formation, GPP over the region was in the range 20-30 and on the day of genesis (29 November 2017) it exceeded the threshold (>30). Earlier studies have shown that upper ocean heat content plays an important role in the genesis and intensification of cyclones over the Bay of Bengal, as warm subsurface water helps compensate the wind-driven mixing-induced cooling during a cyclone $\mathrm{e}^{29,30}$. It has been estimated that a minimum of $30 \mathrm{~kJ} \mathrm{~cm}^{-2}$ upper ocean heat content is necessary to favour intensification in the Bay of Bengal $^{29}$. A recent example is cyclone Nargis in the Bay of Bengal, which intensified rapidly when it moved over a region of high upper ocean heat content ${ }^{31}$. This shows that along with SST and atmospheric parameters, upper ocean heat content also plays a major role in cyclone genesis and intensification. Therefore, this motivated us to consider the modified GPP (eq. (4)), which includes the upper ocean heat content in addition to other atmospheric parameters.
The modified GPP showed that the genesis signal of cyclone development started in the southwest Bay of Bengal and Cape Comorin area from 27 November 2017 onwards, with GPP values of 20-30 (Figure $3 f$ ). In the case of atmosphere-only GPP, the value was less than 20 (Figure $3 b$ ). On 28 November 2017, GPP value increased (50-60) over the Cape Comorin region, indicating enhanced chance of cyclone development (Figure $3 \mathrm{~g}$ ) compared to 20-30 for atmosphere-only GPP (Figure $3 c$ ). Thus, the modified GPP which incorporates upper ocean heat content, was higher than the atmosphere-only GPP and consistently gave an indication of cyclone genesis from 27 November onwards. Therefore, modified GPP indicated the signature of genesis of cyclone Ockhi two days in advance compared to the atmosphere-only GPP which showed cyclogenesis signature only one day in advance. This indicates that by considering the ocean subsurface temperatures, the lead time to capture cyclogenesis signature has increased by one day for cyclone Ockhi.

Further, there were large positive SST anomalies persisting in the southwest Bay of Bengal during 26-28 November, along with an active propagation of MJO starting on 26 November from the Indian Ocean (MJO phase 3 ) to the maritime continent (MJO phase 4) with enhanced amplitude, observed in the phase diagram (Figure $4 a$ ) and the OLR anomalies (Figure $4 b$ ). MJO is an eastward-moving wave in the tropical belt associated with enhanced convective activity in the regions from which it passes. Enhanced convection, as indicated by negative OLR anomalies, can be seen rapidly propagating towards the maritime continent. Previous studies have shown that 


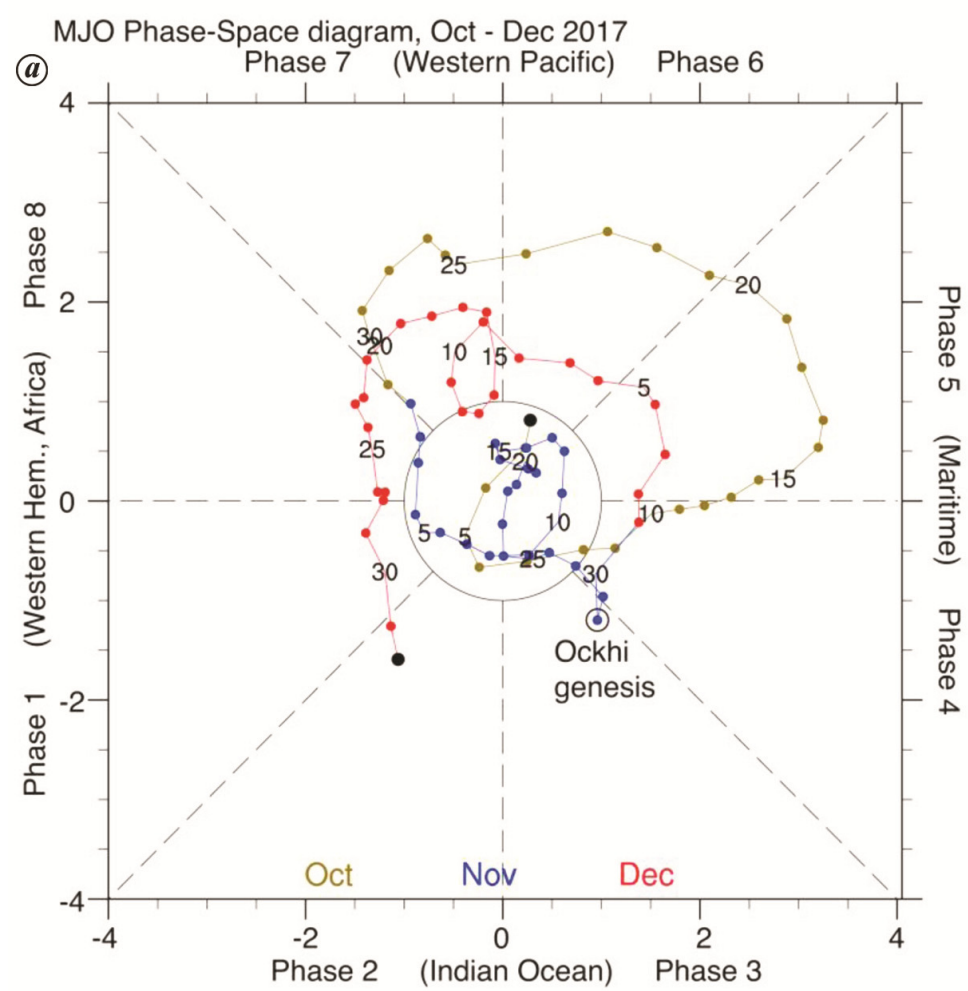

(b) MJO filtered OLR anomalies, Oct - Dec 2017

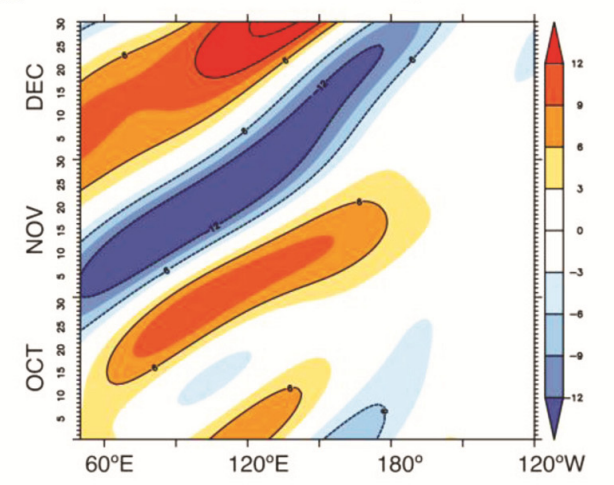

(c) Wind anomalies, 28 Nov - 1 Dec 2017

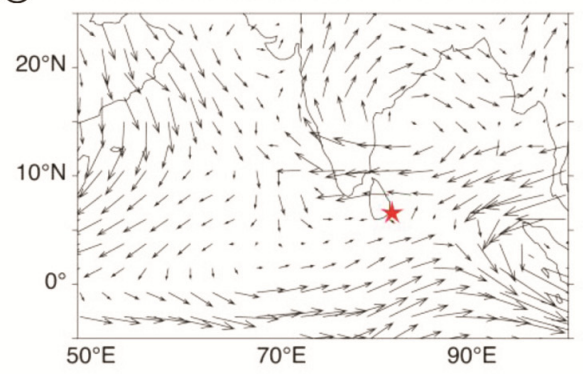

Figure 4. $\boldsymbol{a}$, Phase diagram of Madden-Julian Oscillation (MJO) Real-time Multivariate MJO (RMM) from 1 October to 31 December 2017. Colour denotes the propagation in different months. When the index is within the centre black circle, the MJO activity is considered as weak (below RMM amplitude 1), and when it is outside the circle it is considered as strong (above RMM amplitude 1). b, Propagation of space-time filtered outgoing longwave radiation (OLR) anomalies from August to December 2017. Blue shades denote enhanced convection and red shades denote suppressed convection. $\boldsymbol{c}$, Filtered wind anomalies for MJO at $850 \mathrm{hPa}$ averaged from 28 November to 1 December 2017. Star denotes the genesis of cyclone Ockhi.

MJO in phase 4 is conducive for cyclogenesis in the south of Bay of Bengal by ensuing increased vorticity and anomalous cyclonic circulation on the westward side of MJO-induced convective activity ${ }^{11,12}$. As MJO propagated from phase 3 to phase 4, it resulted in anomalous westerlies over the entire south Bay of Bengal (near the equator) in response to the shift in the convection centre over the maritime continent (Figure $4 c$ ). The anomalous westerlies in the south occurred along with anomalous easterlies over a narrow zone centred near $10^{\circ} \mathrm{N}$. This wind pattern led to the development of cyclonic circulation which along with anomalous high SSTs mentioned above provided conducive conditions for the genesis of cyclone Ockhi over the southwest Bay of Bengal.

\section{Rapid intensification of cyclone Ockhi at its early and mature stages}

During its life cycle, cyclone Ockhi underwent rapid intensification twice - first during its initial stage, and later in its mature stage. During the initial stage, it intensified rapidly from a depression to a cyclonic storm from 29 November 1800 UTC to 30 November 0300 UTC in a span of just $9 \mathrm{~h}$. Large positive SST anomalies up to $0.8^{\circ} \mathrm{C}$ were observed over the south Arabian Sea, espe- cially over Lakshadweep Sea, which persisted from 26 to 30 November (Figures $5 a-d$ and $6 a-d$ ). These large positive SST anomalies were conducive to persistent increase in humidity over the region, as observed in the specific humidity anomalies, which were as large as 8 $12 \mathrm{~g} \mathrm{~kg}^{-1}$ (Figure $5 f-i$ ). High SST and specific humidity anomalies potentially led to thermodynamically unstable conditions, as observed from the increase in difference of equivalent potential temperature anomalies between 1000 and $700 \mathrm{hPa}$ (Figure $5 k-n$ ). The enhanced convection was also consistent with the anomalously high CAPE $\left(>300 \mathrm{~J} \mathrm{~kg}^{-1}\right.$ ) (Figure $\left.5 p-s\right)$ over the region. As the depression moved over the region with favourable thermodynamic conditions, it intensified rapidly to a deep depression and further to a cyclone in just $9 \mathrm{~h}$ (Figure $1 b$ ). It can be seen from Figure $2 b$ that in the north Indian Ocean, for the post-monsoon cyclones, the probability of intensification of a system from a depression to a cyclonic storm in less than $12 \mathrm{~h}$ is only 0.2 . This shows that the rapid intensification of a cyclone in its early stage from a depression to a cyclonic storm in only $9 \mathrm{~h}$, as seen in cyclone Ockhi, is a rare occurrence. Prevailing thermodynamic conditions mentioned above favour rapid intensification of cyclones, as shown in previous studies that high SSTs along with thermodynamically unstable 

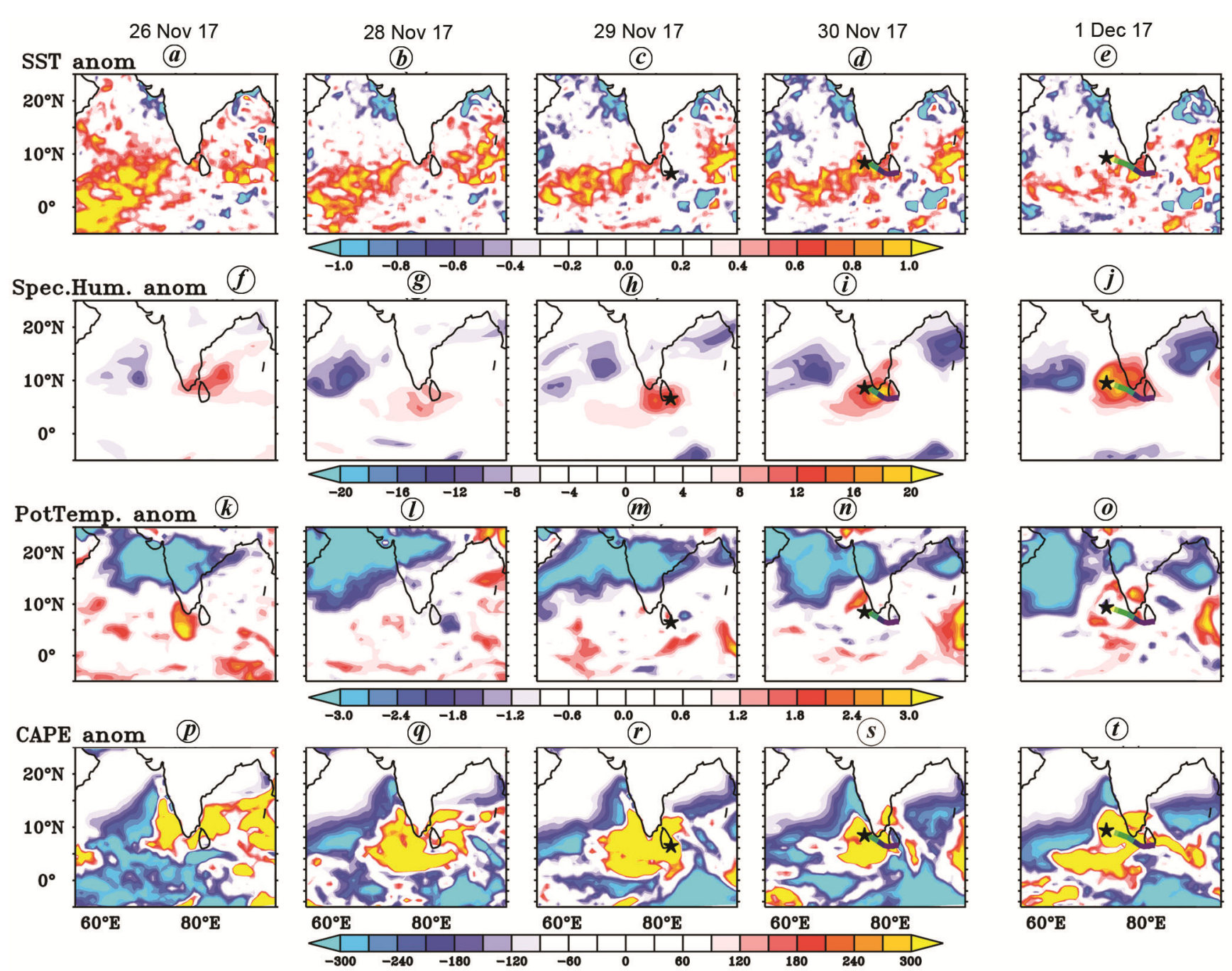

Figure 5. Anomalies of $(\boldsymbol{a}-\boldsymbol{e})$ sea surface temperature (SST) $\left({ }^{\circ} \mathrm{C}\right),(\boldsymbol{f}-\boldsymbol{j})$ vertically integrated $(850-400 \mathrm{hPa})$ specific humidity $\left(\mathrm{g} \mathrm{kg}^{-1}\right),(\boldsymbol{k}-\boldsymbol{o})$ difference of equivalent potential temperature between 1000 and $700 \mathrm{hPa}$, and $(\boldsymbol{p}-\boldsymbol{t})$ convective available potential energy $(\mathrm{CAPE})\left(\mathrm{J} \mathrm{kg}^{-1}\right)$ from 26 November to 1 December 2017. The figures are overlaid with the track of cyclone Ockhi from its day of formation. Star denotes the position of the cyclone on each day (track colour denoting wind speed (kt); same as in Figure $1 b$ ).

atmosphere and large low to middle atmosphere humidity lead to rapid development of cyclones ${ }^{18,32}$. It is to be noted that during the time of rapid intensification in the initial stage, the vertical wind shear over the region was high, reaching up to $20-22 \mathrm{~m} \mathrm{~s}^{-1}$, which is not conducive for intensification (Figure $7 a$ ). Despite the high wind shear, the low pressure system intensified to a cyclone which may be largely due to conducive thermodynamic conditions over that region owing to high SSTs.

Further, in the mature stage, cyclone Ockhi again intensified rapidly from 1 December 0000 UTC to 2 December 0000 UTC. During this time period, it intensified rapidly and reached the very severe cyclonic storm category; its wind speed increased by $30 \mathrm{kt}\left(15.4 \mathrm{~m} \mathrm{~s}^{-1}\right)$ within an interval of only $24 \mathrm{~h}$ (Figure $2 a$ ). This coincided with the movement of the cyclone over the southeast Arabian Sea
(Figure $1 b$ ). This region was also conducive to intensification with high SST anomalies providing large specific humidity and large positive difference in the equivalent potential temperature anomalies between 1000 and $700 \mathrm{hPa}$ (Figure 5). A combination of these factors increased CAPE over the region, in turn making the atmosphere more thermodynamically unstable. These conducive thermodynamic conditions over the southeast Arabian Sea on 30 November and 1 December 2017, led the system to undergo rapid intensification during its mature stage.

From 3 December 2017 onwards, cyclone Ockhi started weakening as it moved over the east-central Arabian Sea and came across below-normal SSTs over the northeast Arabian Sea (Figure $6 b-d$ ). These cool SSTs and low equivalent potential temperatures (Figure $6 j-l$ ) along with high vertical shear of horizontal winds with values exceeding $30 \mathrm{~m} \mathrm{~s}^{-1}$ (Figure $7 c$ and $d$ ) over the 


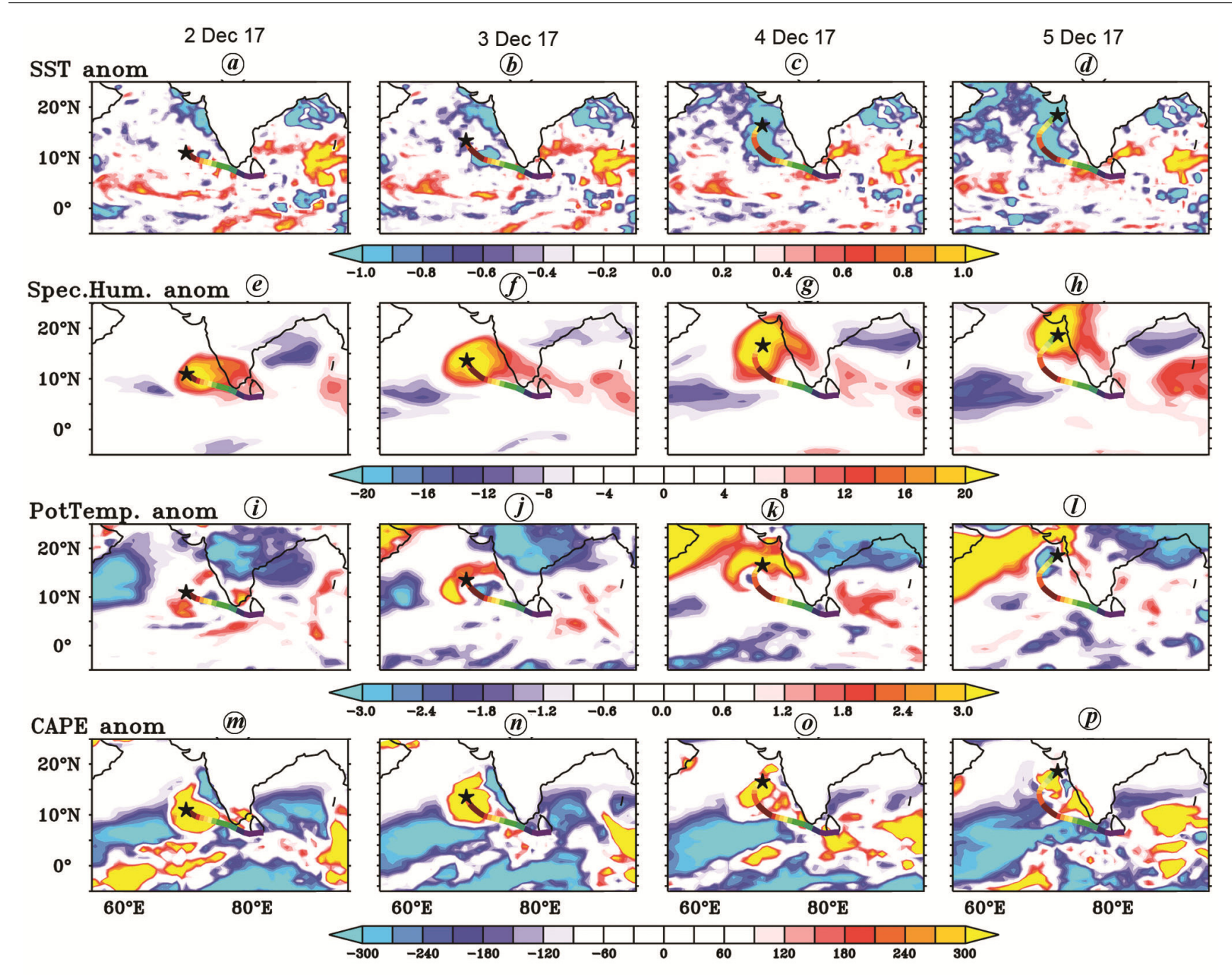

Figure 6. Anomalies of $(\boldsymbol{a}-\boldsymbol{d}) \mathrm{SST}\left({ }^{\circ} \mathrm{C}\right),(\boldsymbol{e}-\boldsymbol{h})$ vertically integrated $(850-400 \mathrm{hPa})$ specific humidity $\left(\mathrm{g} \mathrm{kg}^{-1}\right),(\boldsymbol{i}-\boldsymbol{l})$ difference of equivalent potential temperature between 1000 and $700 \mathrm{hPa}$ and $(\boldsymbol{m}-\boldsymbol{p})$ CAPE $\left(\mathrm{J} \mathrm{kg}^{-1}\right)$ from 2 to 5 December 2017. The figures are overlaid with track of cyclone Ockhi from its day of formation. Star denotes the position of the cyclone on each day (track colour denoting wind speed (kt); same as in Figure $1 b$ ).

region led to unfavourable conditions for the cyclone and a reduction in its intensity from $85 \mathrm{kt}\left(43.7 \mathrm{~m} \mathrm{~s}^{-1}\right)$ on 3 December to $65 \mathrm{kt}\left(33.4 \mathrm{~m} \mathrm{~s}^{-1}\right)$ on 4 December 2017. By 5 December 0300 UTC, the intensity of cyclone Ockhi further reduced to $45 \mathrm{kt}\left(23.2 \mathrm{~m} \mathrm{~s}^{-1}\right.$; cyclonic storm). Thereafter, it weakened rapidly to a depression by 5 December 1500 UTC (Figure $2 a$ ), over the northeast Arabian Sea. The storm-induced SST cooling is clearly visible along the track of cyclone Ockhi in Figure $6 b-d$ with an average cooling of $1.4^{\circ} \mathrm{C}$ over the region $68^{\circ}-$ $72^{\circ} \mathrm{E}, 10^{\circ}-17^{\circ} \mathrm{N}$ from 2 to 5 December, and a maximum cooling of up to $3.8^{\circ} \mathrm{C}$ on 5 December 2017 . This shows that there is two-way feedback between cyclone Ockhi and the ocean underneath. While warm SSTs in the southeast Arabian Sea intensified the cyclone in the initial stages, the persisting clouding and wind-induced upwelling during the peak stage of the cyclone induced a large cooling of SSTs. The anomalous cool SSTs led to a suppression of convective activity in the wake of the cyclone to its rear and adjacent to its track.
ACE calculated using eq. (2) during cyclone Ockhi was $9.29\left(10^{4} \mathrm{kt}^{2}\right)$, which is about 2.5 times higher than the climatological ACE. The climatological ACE calculated based on IMD cyclone data for the Arabian Sea postmonsoon season (October-December) during the period 1990-2016 was $3.69\left(10^{4} \mathrm{kt}^{2}\right)$.

\section{Track of cyclone Ockhi}

Cyclone Ockhi developed as a depression on 29 November 20170300 UTC in the Lakshadweep Sea, south of Cape Comorin (Figure $1 \mathrm{~b}$ ). Initially it moved westward from 29 to 30 November under the influence of upper level $(400-200 \mathrm{hPa})$ easterlies between $5^{\circ} \mathrm{N}$ and $10^{\circ} \mathrm{N}$ (Figure $7 e$ ). By 1 December 0900 UTC, it further intensified to a very severe cyclonic storm with sustained wind speed of $65 \mathrm{kt}\left(33.4 \mathrm{~m} \mathrm{~s}^{-1}\right)$ over the southeast Arabian Sea and moved northwestward (Figure $7 f$ ). It continued to move in the northwest direction till 2 December and attained a peak wind speed of $85 \mathrm{kt}\left(43.7 \mathrm{~m} \mathrm{~s}^{-1}\right)$. From 3 


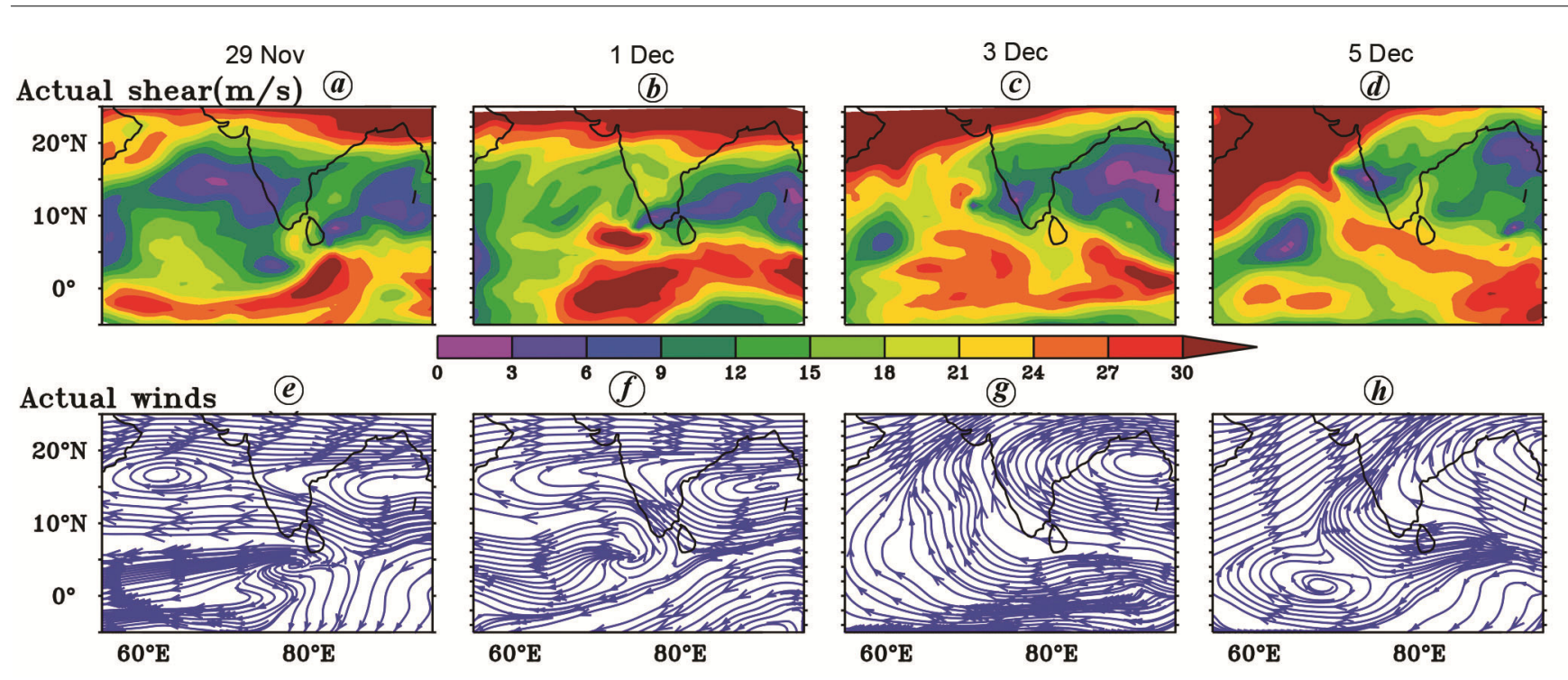

Figure 7. $\boldsymbol{a}-\boldsymbol{d}$, Observed shear (colour; m/s). $\boldsymbol{e}-\boldsymbol{h}$, Upper level (400-200 hPa) wind streamlines during cyclone Ockhi from $29 \mathrm{November}$ to 5 December 2017.

December 0300 UTC, cyclone Ockhi changed its direction due to the influence of an upper-level anticyclone which was anchored over the eastern parts of the Indian subcontinent (Figure $7 g$ and $h$ ). This anticyclone provided southerly steering over the central Arabian Sea, resulting in the cyclone to move in a northward direction. It continued on the same track till 4 December 1500 UTC. By 4 December 1800 UTC, the intensity of the cyclone had reduced to a severe cyclonic storm and it moved in the northeastward direction, due to the influence of the upper level anticyclone (aforementioned), which provided southwesterly steering over the northeast Arabian Sea.

\section{Conclusion}

Cyclone Ockhi, formed on 29 November 2017 over the Lakshadweep Sea, south of Cape Comorin, is the first very severe cyclone to form in this region after 1925. It attained a maximum wind speed of $85 \mathrm{kt}\left(43.7 \mathrm{~m} \mathrm{~s}^{-1}\right)$ and maintained the strength of a cyclone for five consecutive days. The present analysis using a modified-GPP shows that along with atmospheric conditions, the ocean surface and subsurface also played a significant role in cyclogenesis and indicates probable genesis two days in advance. Modified GPP, which includes estimates of ocean heat content is always higher than GPP which only includes atmospheric conditions. Further, favourable MJO conditions from 26 November 2017 provided conducive background winds that enhanced the existing cyclonic circulation to sustain and grow to a depression. Meanwhile, anomalous warm SSTs of up to $0.8^{\circ} \mathrm{C}$ led to a thermodynamic enhancement of convective activity over the region, leading to a rapid intensification of the cyclone on 29 November 2017. Further, cyclone Ockhi intensified rapidly from a cyclonic storm to a very severe cyclonic storm on 1 December 2017 over the southeast Arabian Sea due to the persistent favourable thermodynamic conditions over the region. Prolonged warm SSTs over large parts of the south-southeast Arabian Sea led cyclone Ockhi to maintain its strength for five consecutive days leading to large ACE, which was 2.5 times more than normal.

SST was an important factor which contributed to the sudden and rapid changes in the intensity of cyclone Ockhi. Earlier studies have shown that SST plays a major role in enhancing ACE, indicating long duration and high intensity of cyclones ${ }^{33}$. In terms of ACE, cyclone Ockhi was the fourth strongest cyclone in the Arabian Sea during the post-monsoon season in the last 28 years. This is in line with a recent study which shows that anthropogenic warming has increased the probability of extremely severe cyclones occurring in the Arabian Sea during the post-monsoon season ${ }^{34}$. The track of cyclone Ockhi was mainly steered by the upper level (400-200 hPa) winds. An anticyclone over eastern parts of the Indian land mass at the upper tropospheric levels was responsible for recurvature (northeastward) in the track after 3 December 2017. By 5 December 1500 UTC, cyclone Ockhi encountered unfavourable conditions, including cold SST, low equivalent potential temperature and a strong wind shear, thus weakening it rapidly to a depression and dissipating thereafter.

The state-of-the-art models used for cyclone forecasting have uncertainties due to lack of skilful coupling between atmosphere and ocean ${ }^{10}$. The present analysis thus highlights that ocean surface and subsurface conditions played a vital role in the genesis and intensification of cyclone Ockhi. It is hence important to improve the coupling between atmosphere and ocean, and incorporate ocean subsurface conditions more precisely into the cyclone forecasting models in order to improve the 
prediction skills with high lead time. Generally, the cyclones which form in the Arabian Sea make a landfall causing severe damage to life and property in the densely populated Indian Ocean rim countries ${ }^{35}$. Hence it is imperative to closely monitor the basin for future storms as climate models project continued rapid warming of the Indian Ocean, especially the Arabian $\mathrm{Sea}^{36}$.

Conflict of interest: The authors declare that they have no conflict of interest.

1. Gray, W. M., Tropical cyclone genesis. Department of Atmospheric Science Paper No. 234, Colorado State University, USA, 1975, p. 121.

2. Mandal, G. S., Tropical cyclones and their forecasting and warning systems in the north Indian Ocean, WMO/TD-No. 430, Tropical Cyclones Program, Report No. TCP-28, World Meteorological Organization, Geneva, 1991.

3. Neumann, B., Vafeidis, A. T., Zimmermann, J. and Nicholls, R. J., Future coastal population growth and exposure to sea-level rise and coastal flooding - a global assessment. PLOS ONE, 2015, 10, e0118571.

4. GoI, Cyclone forecast, Ministry of Home Affairs, Government of India, Question no. 4065, 2018

5. Guha-Sapir, D., EM-DAT: The OFDA/CRED International Disaster Database, http://emdat.be/

6. GoI, Cyclone forecast, Ministry of Earth Sciences, Government of India, Question no. 2710, 2018.

7. Mohapatra, M., Nayak, D. P., Sharma, M., Sharma, R. P. and Bandyopadhyay, B. K., Evaluation of official tropical cyclone landfall forecast issued by India Meteorological Department. $J$. Earth Syst. Sci., 2013, 122, 589-601.

8. India Meteorological Department, Report on cyclonic disturbances over north Indian Ocean during 2017. Regional Specialized Meteorological Centre-Tropical Cyclones, No. ESSO/IMD/CWD Report No-01 (2018)/15, 2018

9. IMD, Cyclone atlas - tracks of cyclones and depressions over north Indian Ocean (from 1891 onwards). Electronic version 2.0/2011 Cyclone Warnings and Research Center, India Meteorological Department, Chennai, 2011.

10. Mohanty, S., Nadimpalli, R., Osuri, K. K., Pattanayak, S., Mohanty, U. C. and Sil, S., Role of sea surface temperature in modulating life cycle of tropical cyclones over Bay of Bengal. Trop. Cyclone Res. Rev., 2019, 8, 68-83.

11. Klotzbach, P. J., The Madden-Julian Oscillation's impacts on worldwide tropical cyclone activity. J. Climate, 2014, 27, 23172330.

12. Krishnamohan, K. S., Mohanakumar, K. and Joseph, P. V., The influence of Madden-Julian Oscillation in the genesis of north Indian Ocean tropical cyclones. Theor. Appl. Climatol., 2012, 109, 271-282.

13. Tyagi, A., India Meteorological Department Forecaster's Guide, Pune, India, 2008, p. 16.

14. Knapp, K. R., Kruk, M. C., Levinson, D. H., Diamond, H. J. and Neumann, C. J., The International Best Track Archive for Climate Stewardship (IBTrACS). Bull. Am. Meteorol. Soc., 2010, 91, $363-$ 376.

15. Reynolds, R. W., Smith, T. M., Liu, C., Chelton, D. B., Casey, K. S. and Schlax, M. G., Daily high-resolution-blended analyses for sea surface temperature. J. Climate, 2007, 20, 5473-5496.

16. Dee, D. P. et al., The ERA-Interim reanalysis: configuration and performance of the data assimilation system. Q. J. R. Meteorol. Soc., 2011, 137, 553-597.

17. Roxy, M. and Tanimoto, Y., Role of SST over the Indian Ocean in influencing the intraseasonal variability of the Indian summer monsoon. J. Meteorol. Soc. Jpn, 2007, 85, 349-358.
18. Gray, W. M., Hurricane and their formation structure and likely role in the tropical circulation. Prepared for the RMS/AMS Conference on Meteorology over the Tropical Oceans, London, 21-25 August 1978 and RMS Conference Volume, 1978.

19. Camargo, S. J. and Sobel, A. H., Western North Pacific tropical cyclone intensity and ENSO. J. Climate, 2005, 18, 2996-3006.

20. Bell, G. D. and Chelliah, M., Leading tropical modes associated with interannual and multidecadal fluctuations in north Atlantic hurricane activity. J. Climate, 2006, 19, 590-612.

21. Kotal, S. D., Kundu, P. D. and Bhowmik, S. K. R., Analysis of cyclogeneis parameter for developing and nondeveloping lowpressure systems over the Indian Sea. Nat. Hazards, 2009, 50, 389-402.

22. Gray, W. M., Global view of the origin of tropical disturbances and storms. Mon. Weather Rev., 1968, 96, 669-700.

23. George, J. J., Weather Forecasting for Aeronautics, Academic Press, USA, 1960, p. 673.

24. Suneeta, P. and Sadhuram, Y., Tropical cyclone genesis potential index for Bay of Bengal during peak post-monsoon (OctoberNovember) season including atmosphere-ocean parameters. Mar. Geod., 2018, 41, 86-97.

25. Leipper, D. F. and Volgenau, L. D., Hurricane heat potential of the Gulf of Mexico. J. Phys. Oceanogr., 1972, 2(3), 218-224.

26. Kalnay, E. et al., The NCEP/NCAR 40-year reanalysis project. Bull. Am. Meteorol. Soc., 1996, 77, 437-472.

27. Wheeler, M. C. and Hendon, H. H., An all-season real-time multivariate MJO index: development of an index for monitoring and prediction. Mon. Weather Rev., 2004, 132, 1917-1932.

28. Kotal, S. D. and Bhattacharya, S. K., Tropical cyclone genesis potential parameter (GPP) and its application over the north Indian Sea. Mausam, 2013, 64, 149-170.

29. Maneesha, K., Sadhuram, Y. and Prasad, K. V. S. R., Role of upper ocean parameters in the genesis, intensification and tracks of cyclones over the Bay of Bengal. J. Oper. Oceanogr., 2015, 8, $133-146$.

30. Patnaik, K. V. K. R. K., Maneesha, K., Sadhuram, Y., Prasad, K. V. S. R., Ramana, T. V. and Rao, V. B., East India coastal current induced eddies and their interaction with tropical storms over Bay of Bengal. J. Oper. Oceanogr., 2014, 7, 58-68.

31. Lin, I. I., Chen, C. H., Pun, I. F., Liu, W. T. and Wu, C. C., Warm ocean anomaly, air sea fluxes, and the rapid intensification of tropical cyclone Nargis (2008). Geophys. Res. Lett., 2009, 36, 2-6.

32. Kotal, S. D. and Roy Bhowmik, S. K., Large-scale characteristics of rapidly intensifying tropical cyclones over the Bay of Bengal and a rapid intensification (RI) index. Mausam, 2013, 64, 13-24.

33. Klotzbach, P. J., Trends in global tropical cyclone activity over the past twenty years (1986-2005). Geophys. Res. Lett., 2006, 33, L10805.

34. Murakami, H., Vecchi, G. A. and Underwood, S., Increasing frequency of extremely severe cyclonic storms over the Arabian Sea. Nature Climate Change, 2017, 7, 885-889.

35. Evan, A. T. and Camargo, S. J., A climatology of Arabian Sea cyclonic storms. J. Climate, 2010, 24, 140-158.

36. Ogata, T. et al., Projected future changes in the Asian monsoon: a comparison of CMIP3 and CMIP5 model results. J. Meteorol. Soc. Jpn, 2014, 92, 207-225.

ACKNOWLEDGEMENTS. The satellite imagery was obtained from NASA-NOAA's Suomi NPP satellite pass on 30 November 2017, 0824 UTC. We thank Panini Dasgupta (Indian Institute of Tropical Meteorology, Pune) for help with the MJO analysis and Swaleha Inamdar for technical assistance with the manuscript.

Received 20 March 2019; revised accepted 15 June 2020

doi: $10.18520 / \mathrm{cs} / \mathrm{v} 119 / \mathrm{i} 5 / 771-779$ 